\title{
The prognostic value of nodal skip metastasis in resectable thoracic esophageal squamous cell carcinoma
}

This article was published in the following Dove Press journal:

OncoTargets and Therapy

25 May 2017

Number of times this article has been viewed

\section{Ge Song ${ }^{1,2, *}$ \\ Wang Jing ${ }^{3, *}$ \\ Song Xue ${ }^{1,2}$ \\ Hongbo Guo ${ }^{4}$ \\ Jinming $Y u^{1,2}$}

'Department of Radiation Oncology, School of Medicine and Life Sciences, University of Jinan-Shandong Academy of Medical Sciences; ${ }^{2}$ Department of Radiation Oncology, Shandong Cancer Hospital Affiliated with Shandong University, Jinan, ${ }^{3}$ Department of Radiation Oncology, the First Affiliated Hospital of Zhengzhou University, Zhengzhou, ${ }^{4}$ Department of Thoracic Surgery, Shandong Cancer Hospital Affiliated with Shandong University, Jinan, China

*These authors contributed equally to the work
Correspondence: Jinming Yu Department of Radiation Oncology, Shandong Cancer Hospital Affiliated with Shandong University, Jiyan Road 440, Jinan 250117 , Shandong Province, China $\mathrm{Tel}+8653$ I 6762697 I

Fax +86 53। 87984079

Email sdyujinming@163.com
Purpose: This study aimed to investigate the incidence of nodal skip metastasis (NSM) to identify the risk factors that influence NSM and to assess the prognostic value of NSM in patients with thoracic esophageal squamous cell carcinoma (ESCC).

Patients and methods: Between January 2009 and December 2013, 285 patients with ESCC with positive lymph nodes who underwent complete resection were enrolled.

Results: For the entire group, NSM occurred in 32.3\% (92/285) of patients. The median survival time and 5-year survival rate in the NSM group were 28 months and $12.0 \%$, respectively, compared with 36.3 months and $25.0 \%$, respectively, in the non-NSM group $(P=0.008)$. Both $\mathrm{N}$ stage $(P=0.001)$ and T stage $(P=0.014)$ were associated with the incidence of NSM. NSM $(P=0.008)$, T stage $(P=0.000)$, and $\mathrm{N}$ stage $(P=0.000)$ were independent prognostic factors for survival. In the NSM group, T stage $(P=0.014)$ and $\mathrm{N}$ stage $(P=0.000)$ were independent prognostic factors for survival.

Conclusion: It was concluded that NSM is common in ESCC and is associated with poor survival.

Keywords: esophageal squamous cell carcinoma, surgery, nodal skip metastasis, incidence, risk factors, prognosis

\section{Introduction}

Esophageal cancer (EC) is the eighth most common cancer worldwide and is the sixth leading cause of cancer-related deaths. ${ }^{1,2}$ EC encompasses two main pathological types - adenocarcinoma and squamous cell carcinoma (SCC). North-Central China is often referred to as the "esophageal cancer belt," and $90 \%$ of cases are esophageal squamous cell carcinoma (ESCC). ${ }^{3}$ Even though the treatment has been evolved in recent years, the long-term outcomes for patients with ESCC remain negative. The 5-year survival rate of patients with ESCC ranges from $26.2 \%$ to $49.4 \% .^{4-8}$

Several studies have attempted to determine the clinical features that influence the prognosis of patients with ESCC. Lymph nodes (LNs) are considered to be the most reliable factor for therapeutic management since they affect the long-term survival of patients with EC after curative resection. ${ }^{9,10}$ It was demonstrated that the number of positive LNs led to different survival times. ${ }^{11-17}$ However, the distribution of LN metastases might be a more valuable factor that reflects the prognosis of patients. ${ }^{18}$ Nodal skip metastasis (NSM) is defined as the presence of infiltrated LNs that are distant from the primary tumor but without the involvement of nodes in close proximity to the primary site. This is a common pathway for metastatic spread in up to $73.6 \%$ 
of EC cases reported in previous studies. ${ }^{19-21}$ NSM has been demonstrated to be a positive prognostic factor in non-small cell lung cancer (NSCLC) and colorectal cancer,;2,23 nevertheless, the role of NSM in EC is still unclear. Several studies that were conducted to evaluate the prognostic value of NSM in EC showed controversial results. ${ }^{19,21,24}$ Recently, a retrospective study that included 207 patients with ESCC who underwent three-field lymphadenectomy indicated no significant difference in the overall survival (OS) between the patients with and without NSM $(P=0.767) .{ }^{19}$ However, the data from the study by Prenzel et al indicated that NSM was a positive prognostic factor for survival. ${ }^{21}$ Prenzel et al assessed the presence of NSM in 128 patients with resectable EC and revealed that the 5-year survival rate was higher in patients with NSM than in those with continuous metastasis (53\% vs $15 \%, P<0.0001)$. Another early study demonstrated that patients with NSM had a poorer 5-year survival rate than those without NSM (48.2\% vs 79.5\%). ${ }^{25}$

Studies on the role of NSM in patients with EC are relatively rare, and the results have been inconsistent and even contradictory. Therefore, the present retrospective study was conducted to further investigate the incidence of NSM in patients with thoracic ESCC, the risk factors that influence NSM, and the prognostic value of NSM.

\section{Patients and methods Study population}

The pathology reports of all patients with EC who underwent two-field lymphadenectomy (2FLND) at Shandong Cancer Hospital Affiliated with Shandong University between January 1, 2009, and November 31, 2013, were reviewed. The inclusion criteria were as follows: pathologically confirmed thoracic ESCC; only one primary tumor site; no distant metastasis at diagnosis; received radical esophagectomy with 2FLND; complete resection; at least 12 LNs removed; only regional LN involvement; no treatments before surgery; and complete clinical data. This study was approved by the Institutional Review Board of the Cancer Hospital of Shandong, which waived the requirement for written informed consent of individual patients since the reviewed data were de-identified and anonymized in this retrospective study.

\section{Treatment procedure}

Standardized transthoracic esophagectomy with 2FLND was performed in all patients. The operation consisted of a left thoracotomy and a collar neck incision. The thoracotomy with a posterolateral incision was usually performed through the left sixth or seventh intercostal space. During the operation, 2FLND was performed, which included the dissection of the middle to lower thoracic and upper abdominal LN stations. The thoracic nodes that were dissected consisted of the hilar, subcarinal, pulmonary ligament, phrenic, and other paraesophageal nodes. Moreover, the abdominal LNs, including the paragastric nodes, and the LNs adjacent to the celiac trunk were also removed. Gastroesophageal reconstruction was achieved by stomach bypass through the posterior mediastinal route, while anastomosis was performed in the neck for all patients. After surgery, all removed nodes were labeled with their anatomical locations and were submitted for pathological examination. The treatment following surgery was based on the corresponding stage.

Postoperative adjuvant treatment consisted of chemotherapy and radiotherapy. For chemotherapy, 4 cycles of platinum combined with 5-fluorouracil or a taxane (docetaxel or paclitaxel) were administered. For patients with concurrent treatment, chemotherapy began on the first day of irradiation. Three-dimensional conformal radiation therapy or intensity-modulated radiation therapy was delivered, which was performed 5 days per week at a dose of $2.0 \mathrm{~Gy}$; the total dose was 50 Gy given in 25 fractions.

\section{Pathology and LN classification}

All LNs were fixed in 5\% formaldehyde and embedded in paraffin. Serial sections of LNs at a thickness of $5 \mu \mathrm{m}$ were analyzed by using routine staining with hematoxylin and eosin for the detection of metastatic involvement. No additional immunohistochemical staining was used to diagnose micrometastases. The numbers and sites of all LNs were recorded. Histopathologic findings were classified according to the Union for International Cancer Control TNM guidelines. ${ }^{24}$ The resected LNs were categorized according to the Japanese staging system of the Japanese Society for Esophageal Disease (JSED) ${ }^{26}$ and were further classified into four categories (Group 1 through Group 4) according to their location relative to the primary tumor. NSM was defined as when LN metastasis was discovered in Group 2, Group 3, or Group 4 beyond Group 1. Group 1 included 101, 105, 106recR, and 106recL in upper ESCC; 106recR, 106recL, and 108 in middle ESCC; and 110, 1, and 2 in lower ESCC.

\section{Follow-up assessment}

Patient follow-up was performed every 3 months up to 2 years, every 6 months up to 5 years, and once yearly thereafter. The regular follow-up assessment included a physical examination, plain chest radiography, endoscopy, and computed tomography of the chest and abdomen. However, examinations were performed sooner if the patient experienced abnormal symptoms. 


\section{Statistical analysis}

Continuous variables were summarized by descriptive statistics, such as the means, medians, and ranges. Categorical variables were tabulated by frequency and percentage. Univariate and multivariate logistic regression models were used to evaluate the associations among clinicopathological characteristics of the patients, primary tumors, and the occurrence of NSM. The Kaplan-Meier method was used to estimate the survival distribution by important categorical parameters. The log-rank test was used to intimate survival differences. Cox-proportional hazards models were performed for the multivariate survival analysis. Survival time was defined as the date of surgery to the date of death or the last follow-up. A two-sided $P<0.050$ was considered statistically significant. All statistical tests were performed with SPSS 17.0 software (SPSS, Chicago, IL, USA).

\section{Results}

\section{Patients}

The characteristics of the patients in the present study are summarized in Table 1. In all, data of 296 patients with ESCC were collected. The median follow-up time was 36.2 months (range: 1.0-85.4 months). By the end of the follow-up period, 11 patients were lost to follow-up and $18.2 \%(52 / 285)$ of patients were still alive. Finally, 285 patients (217 males, 68 females) who met the inclusion criteria were analyzed. The median age of the patients was 61 years (range: $37-72$ years). The median number of resected LNs for the entire cohort was 15 (range: $12-37)$. A total of $58.2 \%$ (166/285) patients received postoperative adjuvant treatment, including $26.0 \%$ (43/166) patients who received chemoradiotherapy, $62.0 \%(103 / 166)$ who received chemotherapy alone, and $12.0 \%(20 / 166)$ who received radiotherapy alone.

\section{Prevalence of NSM}

For the entire group, 32.3\% (92/285) of patients demonstrated NSM, including $81.5 \%$ (75/92) of males and $18.5 \%$ (17/92) of females. NSM mainly occurred in N1 patients (39.5\%, 60/152), while NSM occurred in $23.2 \%$ (22/95) of $\mathrm{N} 2$ patients and $26.3 \%(10 / 38)$ of $\mathrm{N} 3$ patients. The incidence of NSM in patients staged as T4 (40.6\%) was higher than that in patients with other stages (T1, 19.0\%; T2, 34.4\%; T3, $35.1 \%)$. NSM was mainly observed in the upper esophagus $(91.7 \%)$ rather than the middle (32.0\%) and lower esophagus (35.8\%). The relationship between the clinicopathological factors and NSM is shown in Table 2. The univariate analysis demonstrated that only $\mathrm{N}$ stage was associated with the incidence of NSM $(P=0.020)$. However, according to the multivariate analysis, $\mathrm{T}$ stage $(P=0.014, \mathrm{OR}=1.533,95 \%$
Table I Clinicopathological characteristics of 285 patients included in this study

\begin{tabular}{|c|c|}
\hline Characteristics & $\begin{array}{l}\text { Number of } \\
\text { patients (\%) }\end{array}$ \\
\hline \multicolumn{2}{|l|}{ Gender } \\
\hline Male & $217(76.1)$ \\
\hline Female & $68(23.9)$ \\
\hline \multicolumn{2}{|l|}{ Age (years) } \\
\hline$\leq 60$ & I $34(47.0)$ \\
\hline$>60$ & I5I (53.0) \\
\hline \multicolumn{2}{|l|}{ Location of tumor } \\
\hline Upper & $12(4.2)$ \\
\hline Middle & $206(72.3)$ \\
\hline Lower & $67(23.5)$ \\
\hline \multicolumn{2}{|l|}{ Tumor differentiation } \\
\hline Well-differentiated & $5 I(I 7.9)$ \\
\hline Moderately differentiated & I5I (53.0) \\
\hline Poorly differentiated & $83(29.1)$ \\
\hline \multicolumn{2}{|l|}{ T stage } \\
\hline $\mathrm{TI}$ & $58(20.4)$ \\
\hline $\mathrm{T} 2$ & $64(22.5)$ \\
\hline T3 & $79(27.7)$ \\
\hline $\mathrm{T} 4$ & $13(4.6)$ \\
\hline \multicolumn{2}{|l|}{$\mathrm{N}$ stage } \\
\hline $\mathrm{NI}$ & $152(53.3)$ \\
\hline N2 & $95(33.3)$ \\
\hline N3 & $38(13.3)$ \\
\hline \multicolumn{2}{|l|}{ NSM status } \\
\hline No & $92(32.3)$ \\
\hline Yes & $193(67.7)$ \\
\hline \multicolumn{2}{|l|}{ Adjuvant therapy } \\
\hline None & $119(41.8)$ \\
\hline Chemotherapy & $103(36.1)$ \\
\hline Radiotherapy & $20(7.0)$ \\
\hline Chemoradiotherapy & $43(15.1)$ \\
\hline \multicolumn{2}{|c|}{ The number of resected lymph nodes } \\
\hline$\leq 15$ & $182(63.9)$ \\
\hline$>15$ & $103(44.3)$ \\
\hline \multicolumn{2}{|l|}{ Tumor length } \\
\hline$\leq 4$ & $168(53.9)$ \\
\hline$>4$ & $117(36.1)$ \\
\hline
\end{tabular}

Abbreviation: NSM, nodal skip metastasis.

CI: $1.090-2.156)$ and $\mathrm{N}$ stage $(P=0.001, \mathrm{OR}=0.470,95 \%$ CI: 0.297-0.743) were independent influencing factors.

\section{Survival}

The survival curve for the entire group is shown in Figure 1. For the entire group, the median progressionfree survival was 23.1 months (range: $1-76$ months). The median survival time (MST) was 32.5 months (range: 1-84 months), and the 3- and 5-year survival rates were $45.0 \%$ and $23.0 \%$, respectively. The MST in the NSM group was 26.3 months (range: 1.8-77.9 months), while that of the non-NSM group was 36.3 months (range: 1-84 months). The 3- and 5-year survival rates in the 
Table 2 Univariate and multivariate analyses of factors associated with nodal skip metastasis

\begin{tabular}{|c|c|c|c|c|c|}
\hline Characteristics & NSM & Non-NSM & $P$-value (univariate) & $P$-value (multivariate) & HR (95\% Cl) \\
\hline Gender & & & 0.143 & & \\
\hline Male & $75(34.6)$ & $142(65.4)$ & & & \\
\hline Female & $17(25)$ & $51(75)$ & & & \\
\hline Age (years) & & & 0.600 & & \\
\hline$\leq 60$ & $46(34.3)$ & $88(65.7)$ & & & \\
\hline$>60$ & $46(30.5)$ & $105(69.5)$ & & & \\
\hline Location of tumor & & & 0.273 & & \\
\hline Upper & II (9I.7) & I (8.3) & & & \\
\hline Middle & $66(32.0)$ & $140(68.0)$ & & & \\
\hline Lower & $24(35.8)$ & $43(64.2)$ & & & \\
\hline Tumor differentiation & & & 0.489 & & \\
\hline Well-differentiated & I5 (29.4) & $36(70.6)$ & & & \\
\hline Moderately differentiated & $49(32.5)$ & $102(67.5)$ & & & \\
\hline Poorly differentiated & $28(33.7)$ & $55(66.3)$ & & & \\
\hline T stage & & & 0.212 & 0.014 & $1.533(1.090-2.156)$ \\
\hline TI & II (19.0) & $47(8 I)$ & & & \\
\hline $\mathrm{T} 2$ & $22(34.4)$ & $42(65.6)$ & & & \\
\hline T3 & $46(35.1)$ & $85(64.9)$ & & & \\
\hline $\mathrm{T} 4$ & $13(40.6)$ & $19(59.4)$ & & & \\
\hline $\mathrm{N}$ stage & & & 0.020 & 0.001 & $0.470(0.297-0.743)$ \\
\hline NI & $60(39.5)$ & $92(60.5)$ & & & \\
\hline N2 & $22(23.2)$ & $73(76.8)$ & & & \\
\hline N3 & $10(26.3)$ & $28(73.7)$ & & & \\
\hline Tumor length & & & 0.843 & & \\
\hline$\leq 4$ & $55(32.7)$ & $113(67.3)$ & & & \\
\hline$>4$ & $37(31.6)$ & $80(68.4)$ & & & \\
\hline
\end{tabular}

Note: Values are expressed as $n(\%)$.

Abbreviations: NSM, nodal skip metastasis; $\mathrm{HR}$, hazard rate; $\mathrm{Cl}$, confidence interval.

NSM group were $29.0 \%$ and $12.0 \%$, respectively, compared with $50.0 \%$ and $25.0 \%$, respectively, in the non-NSM group $(P=0.008$, OR $=1.453,95 \%$ CI: 1.102-1.915) (Figure 2).

\section{Prognostic factors}

A univariate analysis indicated that $\mathrm{T}$ stage $(P=0.000)$, $\mathrm{N}$ stage $(P=0.000)$, and NSM $(P=0.008)$ were associated with survival. A multivariate analysis revealed that

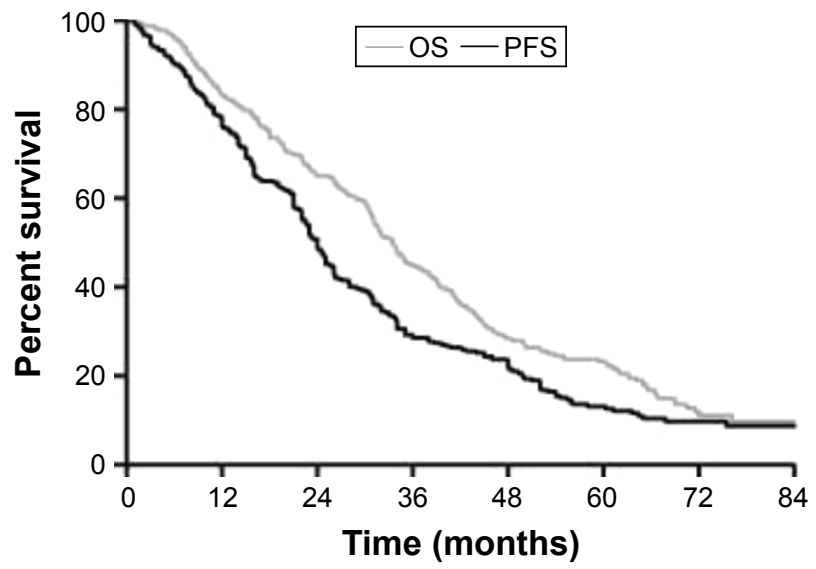

Figure I The PFS and OS for all patients.

Abbreviations: OS, overall survival; PFS, progression-free survival.
T stage $(P=0.000$, OR $=2.403,95 \%$ CI: $2.019-2.859)$, $\mathrm{N}$ stage $(P=0.000, \mathrm{OR}=2.997,95 \% \mathrm{CI}: 2.417-3.717)$, and NSM $(P=0.000$, OR $=2.275,95 \%$ CI: $1.696-3.052)$ were independent prognostic factors for $\mathrm{OS}(P=0.014, \mathrm{HR}=1.509$, 95\% CI: 1.086-2.096) (Table 3). A subgroup analysis was performed on the NSM group, which found that T stage $(P=0.000)$ and $\mathrm{N}$ stage $(P=0.000)$ were associated with $\mathrm{OS}$ in a univariate analysis and that $\mathrm{T}$ stage $(P=0.014, \mathrm{OR}=1.505$,

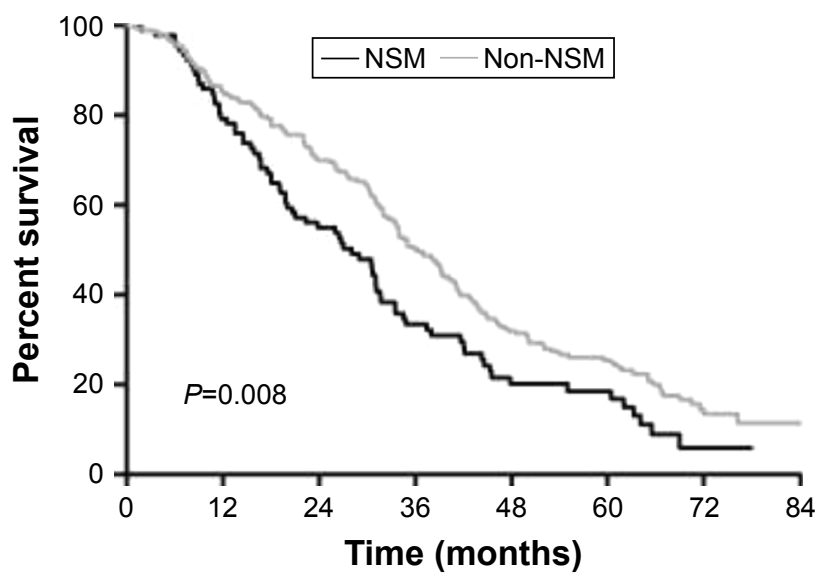

Figure 2 The overall survival for patients with or without NSM. Abbreviation: NSM, nodal skip metastasis. 
Table 3 Univariate and multivariate analyses for overall survival

\begin{tabular}{|c|c|c|c|}
\hline Variable & $\begin{array}{l}\text { P-value } \\
\text { (univariate) }\end{array}$ & $\begin{array}{l}\text { P-value } \\
\text { (multivariate) }\end{array}$ & HR (95\% Cl) \\
\hline $\begin{array}{l}\text { Gender } \\
\text { Male } \\
\text { Female }\end{array}$ & 0.245 & & \\
\hline $\begin{array}{l}\text { Age (years) } \\
\quad \leq 60 \\
>60\end{array}$ & 0.378 & & \\
\hline $\begin{array}{l}\text { Location of tumor } \\
\text { Upper } \\
\text { Middle } \\
\text { Lower }\end{array}$ & 0.321 & & \\
\hline $\begin{array}{l}\text { Tumor differentiation } \\
\text { Well-differentiated } \\
\text { Moderately differentiated } \\
\text { Poorly differentiated }\end{array}$ & $0.4 \mid 4$ & & \\
\hline $\begin{array}{l}\text { T stage } \\
\text { T1 } \\
\text { T2 } \\
\text { T3 } \\
\text { T4 }\end{array}$ & 0.000 & 0.000 & $2.403(2.019-2.859)$ \\
\hline $\begin{array}{l}\text { N stage } \\
\text { NI } \\
\text { N2 } \\
\text { N3 }\end{array}$ & 0.000 & 0.000 & $2.997(2.4|7-3.7| 7)$ \\
\hline $\begin{array}{l}\text { Occurrence of NSM } \\
\text { No } \\
\text { Yes }\end{array}$ & 0.008 & 0.000 & $2.275(1.696-3.052)$ \\
\hline $\begin{array}{l}\text { Adjuvant therapy } \\
\text { None } \\
\text { Chemotherapy } \\
\text { Radiotherapy } \\
\text { Chemoradiotherapy }\end{array}$ & 0.128 & & \\
\hline $\begin{array}{l}\text { The number of resected lymph nodes } \\
\quad \leq 15 \\
>15\end{array}$ & 0.092 & & \\
\hline $\begin{array}{l}\text { Tumor length } \\
\qquad 4 \\
>4\end{array}$ & 0.099 & & \\
\hline
\end{tabular}

Abbreviations: NSM, nodal skip metastasis; $\mathrm{HR}$, hazard rate; $\mathrm{Cl}$, confidence interval.

95\% CI: $1.085-2.089)$ and $\mathrm{N}$ stage $(P=0.000, \mathrm{OR}=5.931$, 95\% CI: 3.554-9.897) were independent prognostic factors for survival in a multivariate analysis.

\section{Discussion}

NSM is defined as infiltration of distant LNs but without tumor involvement in nodes adjacent to the tumor itself. NSM is a well-described phenomenon in NSCLC ${ }^{22}$ as well as in colorectal cancer, ${ }^{23}$ and it is also common in EC. The specific anatomic properties of esophageal lymphatic drainage result in the occurrence of NSM. ${ }^{27}$ The esophagus has two main lymphatic collection areas in the abdomen around the celiac trunk and in the neck and lymphatic vessel communication in the esophageal submucosa is abundant. This lymphatic system not only penetrates the esophageal wall in a transverse manner and drains to adjacent LNs but also participates in more longitudinal communication. Accordingly, the lymphatic flow can easily bypass the LNs located near the primary tumor and travel to distant nodes, which is termed "skipping metastasis."

Data from previous studies showed a significant difference in the prevalence of NSM in EC with a range of 20\%-73.6\%. ${ }^{19-21}$ Chen and Liu divided lymphatic nodes of 1,850 patients into three groups according to the anatomical compartment (cervical, thoracic, or abdominal) and revealed that NSM occurred in $73.6 \%$ of patients with node metastases. ${ }^{20}$ Another retrospective study classified LNs based on the sixth edition of the AJCC Cancer Staging Manual, and only 26\% (58/207) of patients showed NSM. ${ }^{19}$ Prenzel et al divided LN metastases into four categories 
(Group 1 through Group 4) in relation to the primary tumor according to the JSED. Skip metastases were defined as the presence of LNs with no infiltration of Group 1 nodes, but with involvement of Group 2 through Group 4 LNs. NSM was observed in $20.3 \%$ of 128 patients. ${ }^{21}$ However, the present research followed the classification used by Prenzel et al and showed that the rate of NSM was $32.3 \%$. These inconsistent results might be caused by different LN classification systems used for the definition of NSM, selection bias as a result of small sample size, and limitations of retrospective studies.

The results of this study showed that the incidence of NSM increased with the depth of tumor invasion. This may be due to tumor cells that invaded distant LNs along the mucosa that bypassed the local LNs after the submucosal area was infiltrated. However, NSM was found frequently in early $\mathrm{N}$ stage tumors, which can be explained by the abundant lymphatic vessel communication in the esophageal submucosa. The submucosal lymphatic vessel does not drain segmentally, but rather, it drains in a longitudinal fashion. Lymph can travel a long distance in the plexus before it penetrates the esophageal wall and drains to the regional LNs. $^{28}$ This peculiarity of esophageal drainage forms as a result of the existence of extensive skip metastases during the early N stage of esophageal squamous carcinoma in contrast to advanced stages in which metastasis spreads through all possible lymphatic vessels. ${ }^{29}$ On the contrary, advanced $\mathrm{N}$ stage tumors might harbor the presence of NSM. However, data on only $13.3 \%$ (38/285) of N3 patients were collected in the present study. It is therefore reasonable to believe that the incidence of NSM was not substantially impacted by advanced $\mathrm{N}$ stage.

The prognostic value of NSM has been confirmed in NSCLC ${ }^{22}$ and colorectal cancer. ${ }^{23}$ However, few studies have evaluated the role of NSM on the prognosis of patients with $\mathrm{EC}$, and the results of those studies which have been reported were controversial. ${ }^{19,21,24,26,30,31}$ In the study by Prenzel et al, 128 patients with $\mathrm{pN} 1$ stage EC (adenocarcinoma, $\mathrm{n}=67$; SCC, $n=61$ ) were mapped according to the Japanese staging system by the JSED, which showed that patients with NSM had a significantly better 5-year cumulative survival than patients with continuous metastasis (53\% vs $15 \%$; $P<0.0001) .{ }^{21}$ However, Liu et $\mathrm{al}^{31}$ defined station 1 as posterior mediastinal nodes, middle paraesophageal nodes, and lower paraesophageal nodes, which corresponded to upper thoracic, middle thoracic, and lower thoracic, respectively. This classification was based on the sixth edition of the AJCC Cancer Staging Manual and revealed that NSM was associated with a relatively poor prognosis in thoracic ESCC. The 5-year survival rate of patients with NSM was $29.2 \%$, which was significantly worse than the $34.2 \%$ of patients with adjacent node metastasis $(P<0.05) .{ }^{31} \mathrm{Wu}$ et $\mathrm{al}^{30}$ used three classification criteria to define NSM: the JSED, the AJCC Cancer Staging Manual, and the anatomical compartment. Despite the classification criteria, NSM was not a prognostic factor compared with adjacent node metastasis. However, because only 33 patients were involved in Wu et al's study, the conclusion should be further confirmed in a larger sample. These inconsistent results may be due to the different LN classification systems used to define skip metastasis in the former and present studies. The same classification method as that used in the study by Prenzel et al was used in the present study, which led to conflicting results. The 5 -year survival rate of patients with NSM was poorer than that of patients without NSM (12.0\% vs $25.0 \%, P=0.0076)$. The presence of NSM was a risk factor for the prognosis of patients with thoracic ESCC. The biologic behavior and pattern of lymphatic spread may also be different between adenocarcinoma and SCC. ${ }^{25,32}$ Therefore, since only patients with thoracic ESCC were exclusively enrolled in the present study, this may have led to results different from those of the study by Prenzel et al, which contained $52.3 \%$ of patients with adenocarcinoma. Despite the different classification methods used in Liu et al's study and the present study, a similar conclusion is derived. The Japanese staging system used in the present study may provide a more exact staging of regional LNs and more sophisticated assessment of skip metastasis through the division of the locations of LN metastases into four categories (Group 1 through Group 4) according to the position of the lesion. ${ }^{21}$ Therefore, the results of the current research were more credible.

Adequate LN dissection was crucial to the detection of the occurrence of NSM. ${ }^{33}$ All patients in the present study underwent complete 2FLND lymphadenectomy in which $\geq 12$ LNs were harvested. Although no standard was established for the number of resected LNs in order to accurately recognize LN metastasis, a minimum number of 12 used in the present study seems to be sufficient based on the current version of AJCC guidelines. Therefore, false surveillance of NSM due to unreliable LN dissection was avoided in the present study. In addition, as all patients received 2FLND lymphadenectomy, a certain selection bias from different surgeons was surely avoided. Moreover, this study spanned only 4 years, and the therapeutic modality has not evolved over this time period, which precludes variations in therapy. 


\section{Limitations}

The lack of detailed data on LN micrometastasis contributes to the inaccurate diagnosis of NSM. Micrometastases have been frequently observed in EC, and the malignant potential of nodal micrometastatic cancer cells has been confirmed. ${ }^{34,35}$ Small metastases cannot be recognized by conventional histopathological examination, ${ }^{19}$ and whether the presence of small metastases would increase or decrease the rate of NSM is unclear due to the similar likelihood of Group 1-Group 4 LNs to have micrometastatic infiltration. Therefore, if micrometastasis is not taken into account, the diagnosis of NSM may not be very precise, and this has been reported in several previous studies. ${ }^{24,30}$ However, the detection of micrometastasis was beyond the scope of the present study as it has not been routinely assessed in clinical practice for EC. Therefore, further research combined with routine histopathology and immunohistochemistry to identify NSM is needed.

This study has several other limitations that warrant attention. First, since the sequence of LN metastasis cannot be confirmed, the original NSM may be concealed when multiple LN metastasis occurs, which can lead to the inaccurate diagnosis of skip metastasis. Second, the retrospective nature of this study weakened the credibility of the results. In addition, as it was a single-institution series, the sample size was limited, and thus a multi-institutional collaborative study on a large dataset is needed.

\section{Conclusion}

NSM is a common phenomenon in patients with resectable ESCC. The prevalence of NSM is influenced by T stage and $\mathrm{N}$ stage, and the presence of NSM is associated with a negative prognosis of ESCC. Dependence on retrospective studies with small sample sizes to indicate the prognostic value of NSM is inadequate to some extent. The combination of the distribution with the number of LN metastases may provide a more appropriate $\mathrm{N}$-classification for esophageal carcinoma rather than the use of number alone. Further validation using a large-scale or randomized dataset is needed.

\section{Acknowledgments}

This study was supported by the grant from Shandong Provincial Natural Science Foundation (ZR2015HZ004) to Jinming Yu and grant number ZR2011HL029 from the Natural Science Foundation of Shandong Province to Hongbo Guo.

\section{Disclosure}

The authors report no conflicts of interest in this work.

\section{References}

1. Pardo BJD, Bronson NW, Diggs BS, Thomas CR, Hunter JG, Dolan JP. The global burden of esophageal cancer: a disability-adjusted life-year approach. World J Surg. 2015;87(2):395-401.

2. Ferlay J, Shin HR, Bray F, Forman D, Mathers C, Parkin DM. Estimates of worldwide burden of cancer in 2008: GLOBOCAN 2008. Int J Cancer. 2010;127(12):2893-2917.

3. Jemal A, Bray F, Center MM, Ferlay J, Ward E, Forman D. Global cancer statistics. CA Cancer J Clin. 2015;65(2):87-108.

4. Jiang Y, Chen S, Bing Z. Prognostic factors and family history for survival of esophageal squamous cell carcinoma patients after surgery. Ann Thorac Surg. 2010;90(3):908-913.

5. Chen J, Zhu J, Pan J, et al. Postoperative radiotherapy improved survival of poor prognostic squamous cell carcinoma esophagus. Ann Thorac Surg. 2010;90(2):435-442.

6. Yong ELC, Han XP, Watson DI, Devitt PG, Jamieson GG, Thompson SK. Outcome following surgery for squamous cell carcinoma of the oesophagus. ANZ J Surg. 2009;79(10):724-728.

7. Li H, Zhang Q, Xu L, Chen Y, Wei Y, Zhou G. Factors predictive of prognosis after esophagectomy for squamous cell cancer. $J$ Thorac Cardiovasc Surg. 2009;137(1):55-59.

8. Morita M, Yoshida R, Ikeda K, et al. Advances in esophageal cancer surgery in Japan: an analysis of 1000 consecutive patients treated at a single institute. Surgery. 2008;143(4):499-508.

9. Rice TW, Blackstone EH, Rybicki LA, et al. Refining esophageal cancer staging. J Thorac Cardiovasc Surg. 2003;125(5):1103-1113.

10. Zhang HL, Chen LQ, Liu RL, et al. The number of lymph node metastases influences survival and International Union Against Cancer tumor-node-metastasis classification for esophageal squamous cell carcinoma. Dis Esophagus. 2010;23(1):53-58.

11. Kunisaki C, Akiyama H, Nomura M, et al. Developing an appropriate staging system for esophageal carcinoma. J Am Coll Surg. 2005;201(6):884-890.

12. Wilson M, Rosato EL, Chojnacki KA, et al. Prognostic significance of lymph node metastases and ratio in esophageal cancer. J Surg Res. 2008;146(1):11-15.

13. Tachibana M, Yoshimura H, Kinugasa S, et al. Clinicopathologic factors correlated with number of metastatic lymph nodes in oesophageal cancer. Dig Liver Dis. 2001;33(7):534-538.

14. Edge SB, Compton CC. The American Joint Committee on Cancer: the 7 th edition of the AJCC cancer staging manual and the future of TNM. Ann Surg Oncol. 2010;17(6):1471-1474.

15. Rizk N, Venkatraman E, Park B. The prognostic importance of the number of involved lymph nodes in esophageal cancer: implications for revisions of the American Joint Committee on Cancer staging system. J Thorac Cardiovasc Surg. 2006;132(6):1374-1381.

16. Hofstetter W, Correa AM, Bekele N, et al. Proposed modification of nodal status in AJCC esophageal cancer staging system. Ann Thorac Surg. 2007;84(2):374-375.

17. Altorki N, Zhou XB, Port J, Paul S, Lee P, Mazumdar M. Total number of resected lymph nodes predicts survival in esophageal cancer. Ann Surg. 2008;248(2):221-226.

18. Tachibana M, Kinugasa S, Hirahara N, Yoshimura H. Lymph node classification of esophageal squamous cell carcinoma and adenocarcinoma. Eur J Cardiothorac Surg. 2008;34(2):427-431.

19. Zhu Z, Yu W, Li H, et al. Nodal skip metastasis is not a predictor of survival in thoracic esophageal squamous cell carcinoma. Ann Surg Oncol. 2013;20(9):3052-3058.

20. Chen J, Liu SJ. The pattern and prevalence of lymphatic spread in thoracic oesophageal squamous cell carcinoma. Eur J Cardiothorac Surg. 2009;36(3):480-486.

21. Prenzel KL, Bollschweiler E, Schröder W, et al. Prognostic relevance of skip metastases in esophageal cancer. Ann Thorac Surg. 2010;90(5): 1662-1667.

22. Prenzel KL, Baldus SE, Mönig SP, et al. Skip metastasis in nonsmall cell lung carcinoma - predictive markers and isolated tumor cells in N1 lymph nodes. Cancer. 2004;100(9):1909-1917. 
23. Shiozawa M, Akaike M, Yamada R, et al. Clinicopathological features of skip metastasis in colorectal cancer. Hepatogastroenterology. 2007; 54(73):81-84.

24. Hosch SB, Stoecklein NN, Pichlmeier U, et al. Esophageal cancer: the mode of lymphatic tumor cell spread and its prognostic significance. J Clin Oncol. 2001;19(7):1970-1975.

25. Stein HJ, Feith M, Bruecher BL, Naehrig J, Sarbia M, Siewert JR. Early esophageal cancer: pattern of lymphatic spread and prognostic factors for long-term survival after surgical resection. Ann Surg. 2005; 242(4):573-575.

26. Xu QR, Zhuge XP, Zhang HL, Ping YM, Chen LQ. The N-Classification for Esophageal Cancer Staging: should it be based on number, distance, or extent of the lymph node metastasis? World J Surg. 2011; 35(6):1303-1310.

27. Skandalakis JE, Ellis H. Embryologic and anatomic basis of esophageal surgery. Surg Clin North Am. 2000;80(1):85-155.

28. Patti MG, Gantert W, Way LW. Surgery of the esophagus: anatomy and physiology. Surg Clin North Am. 1997;77(5):959-970.

29. An FS, Huang JQ, Chen SH. Analysis of lymph node metastases of 217 cases of thoracic esophageal carcinoma and its impact on prognosis. Ai Zheng. 2003;22(9):974-977.
30. Wu J, Chen QX, Zhou XM, Mao WM, Krasna MJ, Teng LS. Prognostic significance of solitary lymph node metastasis in patients with squamous cell carcinoma of middle thoracic esophagus. World J Surg Oncol. 2012;10(1):210.

31. Liu J, Liu Q, Wang Y, Xia Z, Zhao G. Nodal skip metastasis is associated with a relatively poor prognosis in thoracic esophageal squamous cell carcinoma. Eur J Surg Oncol. 2016;42(8):1202-1205.

32. Siewert JR, Stein HJ, Feith M, Bruecher BL, Bartels H, Fink U. Histologic tumor type is an independent prognostic parameter in esophageal cancer: lessons from more than 1,000 consecutive resections at a single center in the Western world. Ann Surg. 2001;234(3):368-369.

33. Groth SS, Virnig BA, Whitson BA, et al. Determination of the minimum number of lymph nodes to examine to maximize survival in patients with esophageal carcinoma: data from the Surveillance Epidemiology and End Results database. J Thorac Cardiovasc Surg. 2010; 139(3):612-620.

34. Scheunemann P, Izbicki JR, Pantel K. Tumorigenic potential of apparently tumor-free lymph nodes. $N$ Engl J Med. 1999;340(21):1687.

35. Natsugoe S, Matsumoto M, Okumura H, et al. Initial metastatic, including micrometastatic, sites of lymph nodes in esophageal squamous cell carcinoma. J Surg Oncol. 2005;89(1):6-11.
OncoTargets and Therapy

\section{Publish your work in this journal}

OncoTargets and Therapy is an international, peer-reviewed, open access journal focusing on the pathological basis of all cancers, potential targets for therapy and treatment protocols employed to improve the management of cancer patients. The journal also focuses on the impact of management programs and new therapeutic agents and protocols on

\section{Dovepress}

patient perspectives such as quality of life, adherence and satisfaction. The manuscript management system is completely online and includes a very quick and fair peer-review system, which is all easy to use. Visit http://www.dovepress.com/testimonials.php to read real quotes from published authors. 